\title{
Effects of low-intensity endurance and resistance training on mobility in chronic stroke survivors: a pilot randomized controlled study
}

\author{
Nicola LAMBERTI ${ }^{1}$, Sofia STRAUDI ${ }^{2}$, Anna Maria MALAGONI ${ }^{*}$, Matteo ARGIRÒ ${ }^{1}$, Michele FELISATTI ${ }^{4}$, \\ Eleonora NARDINI ${ }^{1}$, Christel ZAMBON ${ }^{1}$, Nino BASAGLIA ${ }^{2}$, Fabio MANFREDINI ${ }^{1,2}$
}

${ }^{1}$ Department of Biomedical Sciences and Surgical Specialties, Section of Sport Sciences, University of Ferrara, Ferrara, Italy; ${ }^{2}$ Department of Rehabilitation Medicine, Ferrara University Hospital, Ferrara, Italy; ${ }^{3}$ Vascular Diseases Center, Unit of Translational Surgery, Ferrara University Hospital, Ferrara, Italy; ${ }^{4}$ Esercizio Vita Nonprofit Cooperative, Ferrara, Italy

*Corresponding author: Anna M. Malagoni, Vascular Diseases Center, Unit of Translational Surgery, Ferrara University Hospital, Via A. Moro 8, Ferrara, 44124, Italy. E-mail: mlgnmr@unife.it

\section{A B S T R A C T}

BACKGROUND: Chronic stroke survivors are exposed to long-term disability and physical deconditioning, effects that may impact their independence and quality of life. Community-based programs optimizing the dose of exercise therapy that are simultaneously low risk and able to achieve high adherence should be identified.

AIM: We tested the hypothesis that an 8-week, community-based, progressive mixed endurance-resistance exercise program at lower cardiovascular and muscular load yielded more mobility benefits than a higher-intensity program in chronic stroke survivors.

DESIGN: A two-arm, parallel-group, pilot randomized, controlled clinical trial.

SETTING: Hospital (recruitment); community-based adapted physical activity center (training).

POPULATION: Thirty-five chronic stroke patients (mean age: $68.4 \pm 10.4$ years; 27 males).

METHODS: Participants were randomized to a low-intensity experimental (LI-E; N.=18) or a high-intensity active control group (HI-C; N.=17) Patients in the LI-E group performed over-ground intermittent walking (weeks 1-8) and muscle power training with portable tools (weeks 5-8); patients in the HI-C group executed treadmill walking (weeks 1-8) and strength training with gym machines (weeks 5-8). Changes in mobility, assessed using the 6-Minute Walking Distance test, were the primary outcome. Secondary outcomes included quality of life (Short-Form-36 Questionnaire), gait speed (10-Meter Walking Test), balance (Berg Balance Scale) and muscle performance of the lower limbs (strength and power of the quadriceps and femoral biceps).

RESULTS: After 8 weeks, the 6MWD revealed more improvement for the LI-E group than the HI-C group ( $\mathrm{P}=0.009)$. The SF36 physical activity domain $(\mathrm{P}=0.012)$ and peak power of the femoral quadriceps and biceps were also significantly improved for the LI-E group ( $\mathrm{P}=0.008$ and $\mathrm{P}<0.001$, respectively) compared with the HI-C. Gait speed, balance and lower-limb strength increased in both groups; no significant differences were noted. The muscle power of the affected limb was the muscle parameter most correlated with mobility in the entire population.

CONCLUSIONS: A low-intensity exercise program exhibited better results in terms of mobility, quality of life and muscle power compared with a higher-intensity program. Data need to be confirmed in a larger trial.

CLINICAL REHABILITATION IMPACT: The effectiveness, low-intensity and possible implementation in poorly equipped community-based settings make the LI-E program potentially suitable for stroke survivors and frail individuals.

(Cite this article as: Lamberti N, Straudi S, Malagoni AM, Argirò M, Felisatti M, Nardini E, et al. Effects of low-intensity endurance and resistance training on mobility in chronic stroke survivors: a pilot randomized controlled study. Eur J Phys Rehabil Med 2017;53:228-39. DOI: 10.23736/S19739087.16.04322-7)

Key words: Clinical trial - Exercise therapy - Mobility limitation - Resistance training - Stroke.

Stroke is one of the leading causes of disability and death worldwide. ${ }^{1}$ Due to demographic shifts in the global population, its burden is bound to enhance despite the stable stroke incidence rate. ${ }^{2,3}$ Stroke survivors are exposed to long-term disability; $15-30 \%$ of individuals exhibit permanent disability; ${ }^{2}$ stroke also 


\section{COPYRIGHT $^{(} 2017$ EDIZIONI MINERVA MEDICA}

has a significant impact on independence, quality of life (QoL) and productivity. ${ }^{4}$ Recovering the ability to walk following a stroke is a priority in this population 5,6 considering the relationship between gait and postural balance, which amplifies the impact on mobility, functional independence, recovery of activities of daily living and risk of falls. ${ }^{7}$ The limited ambulatory capacity of stroke survivors also affects their ability to perform physical exercise and impedes favorable aerobic adaptations typical of endurance training and the control of cardiovascular risk factors ${ }^{8}$ related to mortality, ${ }^{9}$ which results in these patients having a lower peak oxygen consumption. ${ }^{6}$ Such parameter is also worsened by the progression of sarcopenia with a quantitative decline in muscle mass due to physical inactivity. ${ }^{10}$ Moreover, changes in muscle composition in the paretic thigh have been observed after a stroke. ${ }^{10}$ Thus far, several systematic reviews and meta-analyses have provided evidence that aerobic exercise and resistance strength training are beneficial for improving aerobic capacity, walking distance, muscular strength and physical function in stroke survivors, without increasing pain or tone in the paretic limbs. ${ }^{11-17}$ Progressive resistance training has also been shown to improve muscle composition, to evoke significant hypertrophy and to positively regulate myostatin after a stroke. ${ }^{10}$ However, the controversial issue of a possible negative correlation between aerobic and resistance training, ${ }^{18-21}$ patients' limited functional capacity and fatigability 6 and psychological and environmental barriers to starting a physical activity program ${ }^{6}$ may affect the development of effective and sustainable exercise training programs for stroke rehabilitation. Considering the fatigue threshold and the risk of cardiac complications, tailored programs adequately addressing the so-called FITT components (frequency, intensity, time and type of exercise), 22 particularly in terms of intensity, may ensure safety and eligibility of a large number of patients. When available in community-based settings, such tailored programs may also offer high diffusibility, providing an effective response to the progressive increase of stroke survivors and their longterm management. In light of these issues and our previous experience with restricted-mobility patients, ${ }^{23-25}$ we have designed and carried out a lower-intensity (moderate-intermittent endurance and muscle power training) program that makes use of low-cost instruments.

This study aims to determine the effects of an 8-week, low-intensity, supervised original program for chronic stroke survivors. The program, which focuses on mobility, balance and muscular performance parameters, is compared with a high-intensity exercise program combining two effective established interventions based on endurance and strength training.

\section{Materials and methods}

\section{Study design and setting}

This study was a pilot randomized, single-center trial with two arms and parallel groups. It was conducted by the Department of Rehabilitation Medicine of Ferrara University Hospital, in association with the Esercizio Vita adapted physical activity center. The local ethics committee approved the study (number 33/2013).

\section{Randomization}

Web-based simple randomization was performed by an investigator not involved in the trial according to a computer-generated list with an allocation ratio of $1: 1$ (experimental-to-active control group). The randomization process included also an allocation concealment, with the method of the opaque sealed envelopes. The physician responsible for the recruitment of the patients could not be aware of the randomization list.

\section{Enrollment}

From September 2013 through May 2015, eligible subjects were selected from a cohort of chronic stroke patients who were referred to the outpatient clinic of the Rehabilitation Medicine of the Hospital-University of Ferrara. Written, informed consent was obtained from all of the participants. The inclusion criteria included ischemic or hemorrhagic stroke occurring at least 180 days prior to enrolment; an age between 20 and 80; the ability to walk at least 10 meters on level ground; a Functional Ambulation Category score $\geq 3$; stable clinical conditions.

The exclusion criteria included abdominal aortic aneurysms; unstable chronic disease; life-incapacitating cardiac disease (New York Heart Association class III and higher); amputations or any clinical condition that contraindicates or limited walking or treadmill testing; severe balance impairment; psychiatric illness; cogni- 


\section{COPYRIGHT ${ }^{\odot} 2017$ EDIZIONI MINERVA MEDICA}

LAMBERTI

LOW-INTENSITY TRAINING IN CHRONIC STROKE SURVIVORS

tive function impairment (Mini Mental State Examination score $<24$ ); botulinum treatment of the lower limbs within the last 6 months; any physical training or rehabilitation program within the last 6 months.

\section{Interventions}

After we assigned the recruited patients to one of the two study groups, we initiated the scheduled intervention within 4 weeks. Every intervention lasted 8 consecutive weeks and consisted of 24 supervised training sessions, each approximately 1 hour ( 3 sessions/week) and two patients of the same group were simultaneously trained. All of the training sessions were administered by the same expert exercise physiologist at the adapted physical activity center of Esercizio Vita Nonproft Cooperative. Before the starting of the pilot trail, the trainer selected under- went a 6-month period of specific training at the Department of Rehabilitation Medicine of the Hospital-University of Ferrara. For both groups, the 8-week program was divided into an endurance phase based on walking training (weeks 1-4) followed by a mixed phase (weeks 5-8) mainly focusing on muscle-strength training. Each session included a period of warm up and cool down. The trainer was instructed to give patients semi-passive assistance in case their spasticity prevented the patients from executing a satisfying range of movement when performing the resistance or power exercises.

\section{LOW-INTENSITY EXPERIMENTAL GROUP (LI-E)}

Endurance phase.-This period was based on a structured walking program previously employed in patients with chronic diseases, including stroke survivors, $23-25$

TABLE I.-Training program per each exercise session for both groups.

\begin{tabular}{|c|c|c|c|c|c|c|c|c|c|c|c|c|c|c|c|}
\hline \multirow{3}{*}{ Walk } & \multirow{3}{*}{$\begin{array}{l}\text { Ses- } \\
\text { sion }\end{array}$} & \multicolumn{7}{|c|}{ Low-intensity experimental group } & \multicolumn{7}{|c|}{ High-intensity active control group } \\
\hline & & \multicolumn{3}{|c|}{ Aerobic } & \multirow{2}{*}{$\frac{\text { Stretching }}{\begin{array}{c}\text { Duration } \\
(\mathrm{min})\end{array}}$} & \multicolumn{3}{|c|}{ Resistance } & \multicolumn{3}{|c|}{ Aerobic } & \multirow{2}{*}{$\frac{\text { Stretching }}{\begin{array}{c}\text { Duration } \\
(\min )\end{array}}$} & \multicolumn{3}{|c|}{ Resistance } \\
\hline & & $\begin{array}{l}\text { Walk:rest } \\
\text { (min) }\end{array}$ & Reps* & $\begin{array}{c}\text { Speed } \\
\text { (steps/ } \\
\text { min) }\end{array}$ & & Reps & Series & $\begin{array}{l}\text { Load } \\
(\% 1- \\
\text { RM) }\end{array}$ & $\begin{array}{l}\text { Walk:rest } \\
\text { (min) }\end{array}$ & Reps & $\begin{array}{c}\text { Speed } \\
(\% \text { HRR })\end{array}$ & & Reps & Series & $\begin{array}{l}\text { Load } \\
(\% 1- \\
\mathrm{RM})^{\dagger}\end{array}$ \\
\hline \multirow[t]{3}{*}{1} & 1 & $1: 1$ & 10 & $80 \pm 4$ & 10 & \multirow{3}{*}{\multicolumn{3}{|c|}{ Not scheduled }} & $30: 1$ & 1 & $60-70 \%$ & 10 & & Not sched & led \\
\hline & 2 & & & $80 \pm 4$ & & & & & & & & & & & \\
\hline & 3 & & & $84 \pm 4$ & & & & & & & & & & & \\
\hline \multirow[t]{3}{*}{2} & 4 & $1: 1$ & 10 & $84 \pm 4$ & 10 & \multirow{3}{*}{\multicolumn{3}{|c|}{ Not scheduled }} & $30: 1$ & 1 & $60-70 \%$ & 10 & & Not sched & led \\
\hline & 5 & & & $88 \pm 4$ & & & & & & & & & & & \\
\hline & 6 & & & $88 \pm 4$ & & & & & & & & & & & \\
\hline \multirow[t]{3}{*}{3} & 7 & $1: 1$ & 10 & $92 \pm 4$ & 10 & \multirow{3}{*}{\multicolumn{3}{|c|}{ Not scheduled }} & $30: 1$ & 1 & $60-70 \%$ & 10 & & Not sched & led \\
\hline & 8 & & & $92 \pm 4$ & & & & & & & & & & & \\
\hline & 9 & & & $96 \pm 4$ & & & & & & & & & & & \\
\hline \multirow[t]{3}{*}{4} & 10 & $1: 1$ & 10 & $96 \pm 4$ & 10 & \multirow{2}{*}{\multicolumn{3}{|c|}{ Not scheduled }} & $30: 1$ & 1 & $60-70 \%$ & 10 & & Not sched & led \\
\hline & 11 & & & $100 \pm 4$ & & & & & & & & & & & \\
\hline & 12 & & & $100 \pm 4$ & & & & & & & & & & & \\
\hline \multirow[t]{3}{*}{5} & 13 & $2: 1$ & 5 & $66 \pm 3$ & 5 & 5 & 5 & $40-50 \%$ & $10: 1$ & 1 & $60-70 \%$ & 5 & 8 & 3 & $70 \%$ \\
\hline & 14 & & & $66 \pm 3$ & & & & & & & & & & & \\
\hline & 15 & & & $69 \pm 3$ & & & & & & & & & & & \\
\hline \multirow[t]{3}{*}{6} & 16 & $2: 1$ & 5 & $69 \pm 3$ & 5 & 5 & 5 & $40-50 \%$ & $10: 1$ & 1 & $60-70 \%$ & 5 & 8 & 3 & $70 \%$ \\
\hline & 17 & & & $72 \pm 3$ & & & & & & & & & & & \\
\hline & 18 & & & $72 \pm 3$ & & & & & & & & & & & \\
\hline \multirow[t]{3}{*}{7} & 19 & $2: 1$ & 5 & $76 \pm 4$ & 5 & 5 & 5 & $40-50 \%$ & $10: 1$ & 1 & $60-70 \%$ & 5 & 8 & 3 & $70 \%$ \\
\hline & 20 & & & $76 \pm 4$ & & & & & & & & & & & \\
\hline & 21 & & & $80 \pm 4$ & & & & & & & & & & & \\
\hline \multirow[t]{3}{*}{8} & 22 & $2: 1$ & 5 & $80 \pm 4$ & 5 & 5 & 5 & $40-50 \%$ & $10: 1$ & 1 & $60-70 \%$ & 5 & 8 & 3 & $70 \%$ \\
\hline & 23 & & & $84 \pm 4$ & & & & & & & & & & & \\
\hline & 24 & & & $84 \pm 4$ & & & & & & & & & & & \\
\hline
\end{tabular}

1-RM: one-repetition maximum; HRR: heart rate reserve; reps: repetitions.

*The aerobic part for the experimental group was performed two times for each session from the $1^{\text {st }}$ to the $4^{\text {th }}$ week; ${ }^{\dagger}$ leg extension/curl was executed at the optimal controlled speed using linear encoder visual feedback for the low-intensity experimental group, whereas for the high-intensity active control group every muscular exercise was performed at a natural, low speed. 


\section{COPYRIGHT $^{(} 2017$ EDIZIONI MINERVA MEDICA}

LOW-INTENSITY TRAINING IN CHRONIC STROKE SURVIVORS

and adapted for the duration of the study. Each of the 12 training sessions included two 10-minute bouts of intermittent walking ( 1 minute of walk, 1 minute of seated rest) separated by a total of 10 minutes of passive mobilization and stretching exercise for the lowerlimb muscles. The two bouts of over-ground walking were performed at a prescribed speed maintained by a metronome. The walking speed underwent a fixed progression after each session, as reported in Table I, with the possibility of reducing the speed by a fixed number of 4 steps/minutes for each session when the speed by was not tolerated by the patient.

Mixed phase.-In this second period, each training session largely focused on targeted resistance exercises. To calculate the optimal load and speed of execution, patients performed a test to determine the force-velocity relationship for each muscle group. Subjects, seated on a physiotherapist bed with their feet not touching the floor, were familiarized with the leg extension movement to assess femoral quadriceps (FQ) strength and power, during a warm-up phase. Next, the patients were provided a linear encoder (ErgoPower, Bosco System Technologies, Rieti, Italy) that fit around their ankle and ankle weights. The patients were then encouraged to exert maximum effort and perform the movement as fast as they could while wearing increasing loads (starting from $2 \mathrm{~kg}$ ); 3 minutes of rest were scheduled between every load progression. The same protocol was used for assessing the strength and power of the femoral biceps (FB) via a leg curl movement with the patient laying down in a prone position. Data collected by the encoder enabled the instantaneous creation of force-velocity plot using specialized software (Muscle Lab, Bosco System Technologies, Rieti, Italy) and the automatic identification of the peak power. The corresponding external load (approximately $40-50 \%$ of the one-repetition maximum, 1-RM) and the speed of execution were also displayed (Figure 1). ${ }^{26}$ The optimal external load previously identified was applied at the ankle of each patient; the encoder was connected to patients' ankle and to a computer to obtain real-time feedback of each movement, to verify its execution at the proper speed previously determined. The training was based, for the FQ and FB of each limb, on five series of five repetitions of leg extensions and leg curl movements separated by 1 minute of rest. In addition to power training, the subjects in the LI-E group performed 5 minutes of stretch-

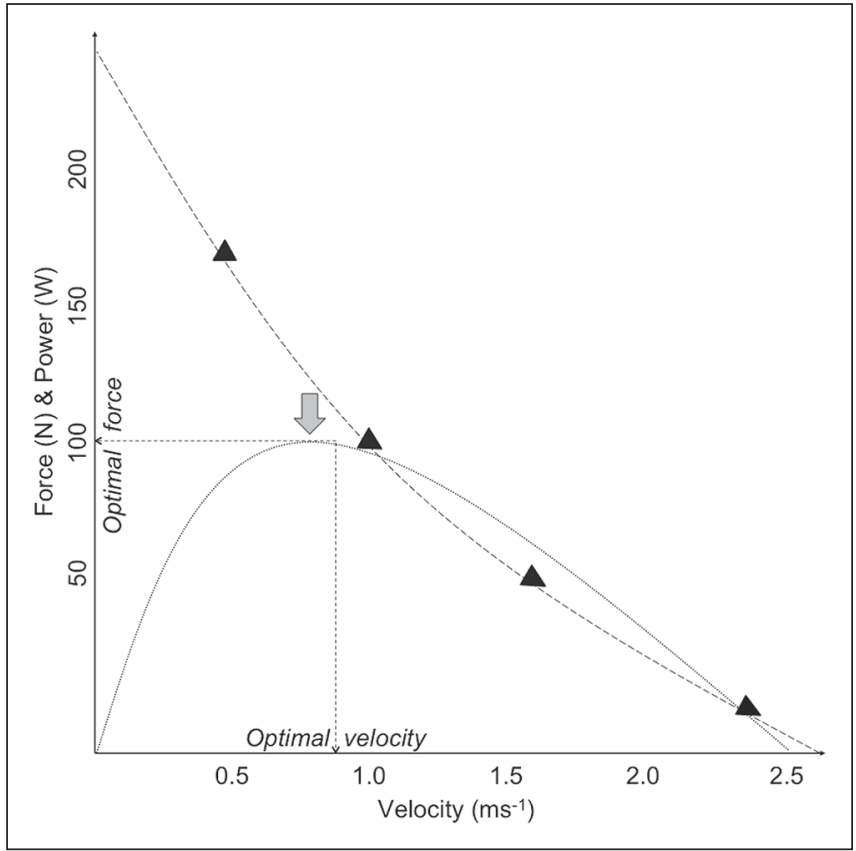

Figure 1.--Representation of the force-velocity (dashed curve) and power-velocity (dotted curve) relationships. Black triangles represent data collected during a test of a single muscle as displayed by the linear encoder. At the peak power (grey arrow) optimal force and velocity, at which the resistance training was performed by Low-intensity experimental group, are located.

ing exercises and a walking session similar to the ones described above composed of five 2-minute walking repetitions separated by 1 minute of rest (Table I). For the FQ and the FB, the affected leg was labeled as weak and the unaffected leg as strong.

\section{HIGH-INTENSITY ACTIVE CONTROL GROUP (HI-C)}

Endurance phase.-This period was based on treadmill walking. As proposed by Ivey et al.,27 the patients performed 30-35 minutes of treadmill walking at 60 $70 \%$ of their Heart Rate Reserve (HRR) calculated according the Karvonen formula. Each session started at $40 \%$ of a patient's HRR for 5 minutes and then advanced to the target range, which was maintained for at least 20 minutes. For the highly-deconditioned patients, training bouts of 5 minutes separated by 1 minute of rest were applied. Handrail support was permitted, and a 5-minute cool-down phase ended the treadmill session. We continuously monitored HR using a HR monitor (Polar RS800CX, Polar Electro Finland). Just like the patients 


\section{COPYRIGHT $^{(} 2017$ EDIZIONI MINERVA MEDICA}

in the other group, the HI-C patients performed a total of 10 minutes of passive mobilization and stretching exercise for their lower-limb muscles.

Mixed phase.-Patients used gym machines (leg extension and leg curl) to exercise the FQ and FB of each limb with 8-10 repetitions with an external load corresponding to $70 \%$ of $1-\mathrm{RM}$. This routine was repeated three times spaced out by 3 minutes of rest. ${ }^{28}$ Next, the patients engaged in stretching exercises for 5 minutes and a 10-minute walking session on the treadmill at 60 $70 \%$ of their HRR (Table I).

\section{Endpoints}

The primary end point was the change in mobility as determined by the 6-Minute Walking Distance (6MWD) at the end of the program with respect to baseline for each group. Secondary end points included changes in QoL and other functional outcomes (balance, gait speed, lower-limb strength and power).

\section{Outcome measures}

Outcomes measures were assessed at baseline (T0) and at the end of the exercise programs (T8). To monitor the adaptations that occurred during each phase, the patients underwent another measurement at the end of the Endurance phase (T4). We also collected baseline demographic data. All of the measurements were carried out at the Esercizio Vita center in a quiet separate area within a temperature-controlled environment in sequence separated by 10-minute intervals from 8:30 a.m. until 12:30 p.m. The expert operators that performed the testing sessions were not blinded to the treatment.

\section{PRIMARY OUTCOME MEASURES}

Mobility.-Mobility was tested with the 6MWD. Patients were instructed to walk along a 22-meter corridor alone at their own pace with the aim of covering as much ground as possible in six minutes. ${ }^{29}$

\section{SECONDARY OUTCOME MEASURES}

Quality of life.-We measured QoL using the Italian version 30 of the Medical Outcomes Study ShortForm 36 Questionnaire (SF-36). The SF-36 contains 36 questions referring to patient health over the previous 4 weeks. It measures 8 specific domains (subscales) including physical functioning (PF), role limitations due to physical problems, bodily pain, general health perception, vitality, social functioning, role limitations due to emotional problems and mental health. Scores for the subscales are expressed on a scale of 0-100 where higher scores correspond to better QoL.

Balance.-We assessed balance using the Berg Balance Scale (BBS). The BBS is a 14-item objective measure designed to assess static balance and fall risk in adult populations. ${ }^{31}$

Gait speed.-We investigated gait speed with a 10 -meter walking test. Patients were asked to walk without assistance at the fastest speed possible for 10 meters; their time was measured at 6 meters (19.7 feet) to allow for acceleration and deceleration. Three trials of this test were conducted for each patient, and the outcome measure that we considered was the average speed of the three trials (10 mWS). ${ }^{29}$

Lower limb strength and power--We measured lower-extremity strength by the five-times sit-to-stand-tosit test (5STS): patients, with their arms crossed on their chests, were asked to move from a sitting position to a standing position from a $43-\mathrm{cm}$-high chair five times as quickly as possible. The execution time was measured with a stopwatch. ${ }^{32}$ We assessed FQ and FB and peak power and strength (i.e., the 1-RM) using a linear encoder already used with elderly people ${ }^{33}$ with the testing procedure described above. MuscleLab software output the data of peak power and 1-RM for both limbs and muscles. A 0 value for strength and power of a specific muscle was assigned when the spastic contraction of that muscle did not allow the patient to perform a load displacement in terms of a range of motion and speed that was sufficient to be recorded by the linear encoder.

\section{Statistical analysis}

We used the Kolmogorov-Smirnov test to confirm the distribution of the variables. The data are presented as mean \pm standard deviation or median (interquartile range) according to their having a normal or a non-normal distribution. We compared the baseline characteristics of the two study groups using Fisher's exact test and the unpaired Student's $t$-test, as appropriate. An intention- 


\section{COPYRIGHT $^{(} 2017$ EDIZIONI MINERVA MEDICA}

to-treat analysis was conducted using multiple imputation to calculate the missing data for subjects who did not complete the study. A between-group comparison was primarily assessed by means of a Student's $t$-test or a Mann-Whitney U-test, as appropriate, considering changes between $\mathrm{T} 0$ and $\mathrm{T} 8$. In addition, we also conducted the same analysis between groups in terms of the variations at the end of the endurance phase compared with baseline. We assessed within-groups comparisons using the paired Student's $t$-test or the Wilcoxon test, as appropriate. We compared the baseline values both with the T8 data and with the data obtained at the end of the endurance phase. The degree of correlation between parameters was obtained using Spearman's rho. A value of $\mathrm{P} \leq 0.05$ was considered to be statistically significant. We analyzed the data using Medcalc v. 16.2.0 (MedCalc Software, Ostend, Belgium) and SPSS Statistics v. 21 (IBM Corp., Armonk, NY, USA).

\section{Results}

Thirty-five of the 51 patients assessed for eligibility were randomized into the two study arms (LI-E: N. $=18$, HI-C: N.=17; Figure 2). The two groups were comparable at baseline in terms of anthropometrics, the number of months from the onset of stroke and outcome measures (Tables II, III). All of the patients were able to perform the leg-extension exercises, and five patients in each group needed the assistance of the trainer when performing the leg curl movement of the $\mathrm{FB}_{\text {weak }}$.

No adverse effects of training were reported.

\section{LI-E group}

Fourteen out of the 18 participants completed all of the training sessions scheduled; four patients were forced to withdraw from the program based on intercurrent diseases that resulted in a treatment suspension lasting more than three weeks $(\mathrm{N} .=2)$ or a surgical intervention $(\mathrm{N} .=2)$. The scheduled walking speed (Table I) was regularly maintained with one-minute bouts ranging from $2.4-3.6 \mathrm{~km} / \mathrm{h}$ (median value of the active phase: $2.9 \mathrm{~km} / \mathrm{h}$; total median value including the resting period: $1.5 \mathrm{~km} / \mathrm{h}$ ) in the endurance phase and two-minute bouts ranging from $1.6-2.6 \mathrm{~km} / \mathrm{h}$ (median value of the active phase: $2.1 \mathrm{~km} / \mathrm{h}$; total median value including the resting period: $1.1 \mathrm{~km} / \mathrm{h}$ ) in the mixed phase. The
HR attained during the walking sessions corresponded to $36 \%$ (range: $31-44 \%$ ) of the HRR. The median load for the power training was $6 \mathrm{~kg}$ (range: $4.5-8.5 \mathrm{~kg}$ ) and $8.5 \mathrm{~kg}$ (range: $5.5-11.0 \mathrm{~kg}$ ) for the $\mathrm{FQ}_{\text {weak }}$ and $\mathrm{FQ}_{\text {strong, }}$, respectively, and $3 \mathrm{~kg}$ (range: $1.0-6.0 \mathrm{~kg}$ ) and $4.5 \mathrm{~kg}$ (range: $4.0-7.0 \mathrm{~kg}$ ) for $\mathrm{FB}_{\text {weak }}$ and $\mathrm{FB}_{\text {strong, }}$, respectively.

\section{HI-C group}

Sixteen out of the 17 patients randomized into this group performed all of the exercise sessions. One patient withdrew due to family problems. The median walking speed set at $60-70 \%$ of the HRR (according to Ivey et al.) ${ }^{30}$ and continuously maintained on the treadmill for approximately 25 minutes was $2.4 \mathrm{~km} / \mathrm{h}$ (range: $1.5-3.6 \mathrm{~km} / \mathrm{h}$ ) in the endurance phase. In the mixed phase, the median walking speed, which was continuously maintained on the treadmill for approximately 10 minutes, was $2.7 \mathrm{~km} / \mathrm{h}$ (range: $1.8-4.0 \mathrm{~km} / \mathrm{h}$ ). The average load for the resistance training was $12.0 \mathrm{~kg}$ (range: 8.0-15.0 kg) and $16.0 \mathrm{~kg}$ (range: $10.5-27.0 \mathrm{~kg}$ ) for the $\mathrm{FQ}_{\text {weak }}$ and $\mathrm{FQ}_{\text {strong, }}$, respectively, and $6.0 \mathrm{~kg}$ (range: 1.5 $12.0 \mathrm{~kg}$ ) and $8.5 \mathrm{~kg}$ (range: $5.5-10.0 \mathrm{~kg}$ ) for the $\mathrm{FB}_{\text {weak }}$ and $\mathrm{FB}_{\text {strong }}$, respectively.

\section{Primary outcome measure}

\section{MoBILITY}

When we compared the variation between T8 and the baseline data, 6MWD exhibited higher values in the LI-E group $(\mathrm{P}=0.009)$ compared with the HI-C group. Even so, 6MWD significantly increased after treatment in both groups (Table III). We also noted a significant difference at the end of the endurance phase with respect to the baseline in the LI-E group compared with the HI-C group $(\mathrm{P}=0.032)$.

\section{Secondary outcome measures}

\section{QUALITY OF LIFE}

When we compared the T8 variation with respect to baseline for the PF domain, the LI-E group registered significantly higher values compared with the HI-C group ( $\mathrm{P}=0.012$ ) (Table III). It is notable that a larger improvement in QoL was already observed at the end of the Endurance phase in the LI-E group versus the HI-C group $(\mathrm{P}=0.027)$. 


\section{COPYRIGHT ${ }^{\circledR} 2017$ EDIZIONI MINERVA MEDICA}

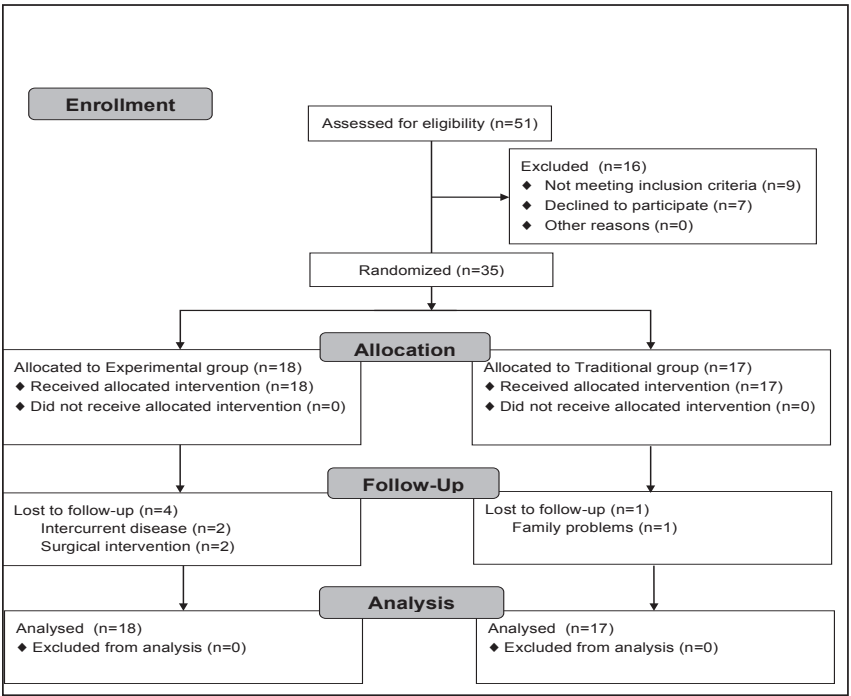

Figure 2.-Flow diagram of the study participants.
TABLE II.-Baseline comparison of demographics and stroke-related data between the two study groups.

\begin{tabular}{lccl}
\hline Patient characteristics & $\begin{array}{c}\text { Low-intensity } \\
\text { experimen- } \\
\text { tal group } \\
\text { (N.=18) }\end{array}$ & $\begin{array}{c}\text { High-intensity } \\
\text { active control } \\
\text { group } \\
\text { (N.=17) }\end{array}$ & P value \\
\hline Age, years & $69 \pm 9$ & $67 \pm 10$ & $\mathrm{NS}$ \\
Male sex, N. (\%) & $14(78 \%)$ & $13(76 \%)$ & $\mathrm{NS}$ \\
Body Mass Index, $\mathrm{kg} / \mathrm{m}^{2}$ & $27 \pm 5$ & $26 \pm 4$ & $\mathrm{NS}$ \\
Distance from stroke, months & $34 \pm 46$ & $40 \pm 51$ & $\mathrm{NS}$ \\
Ischemic stroke, N. (\%) & $16(89 \%)$ & $16(94 \%)$ & $\mathrm{NS}$ \\
Hemiplegia, N. (\%) & $16(89 \%)$ & $16(94 \%)$ & $\mathrm{NS}$ \\
Gait ataxia, N. (\%) & $2(11 \%)$ & $1(6 \%)$ & $\mathrm{NS}$ \\
\hline NS: not statistically significant. & & &
\end{tabular}

\section{BALANCE}

The BBS score exhibited greater variations with respect to the baseline data for the LI-E group, yet the differences were not statistically significant $(\mathrm{P}=0.070)$. We

TABLE III.-Outcome measures, values, and comparison between the two study groups.

\begin{tabular}{|c|c|c|c|c|}
\hline \multirow{2}{*}{ Outcome measures } & \multicolumn{4}{|c|}{$\begin{array}{l}\text { Low-intensity experimental group } \\
\qquad(\mathrm{N} .=18)\end{array}$} \\
\hline & T0 & $\mathrm{T} 4$ & $\mathrm{~T} 8$ & $\Delta \mathrm{T} 8-\mathrm{T} 0$ \\
\hline \multicolumn{5}{|l|}{ Physical functioning } \\
\hline $6 \mathrm{MWD}, \mathrm{m}$ & $230 \pm 107$ & $270 \pm 125 * *$ & $301 \pm 132 * *$ & $71 \pm 44$ \\
\hline BBS score & $49 \pm 5$ & $52 \pm 4 * *$ & $53 \pm 3 * *$ & $4 \pm 3$ \\
\hline $10 \mathrm{mWS}, \mathrm{m} / \mathrm{s}$ & $0.98 \pm 0.41$ & $1.05 \pm 0.40^{*}$ & $1.18 \pm 0.47 * *$ & $0.20 \pm 0.14$ \\
\hline \multicolumn{5}{|l|}{ QoL SF-36 domains } \\
\hline PF & $50 \pm 22$ & $61 \pm 23 * *$ & $66 \pm 19 * *$ & $16 \pm 12$ \\
\hline BP & $78 \pm 24$ & $78 \pm 22$ & $88 \pm 14 *$ & $11 \pm 22$ \\
\hline PR & $76 \pm 31$ & $76 \pm 40$ & $79 \pm 35$ & $3 \pm 34$ \\
\hline GH & $56 \pm 25$ & $61 \pm 22$ & $63 \pm 26$ & $7 \pm 20$ \\
\hline ER & $82 \pm 26$ & $80 \pm 26$ & $87 \pm 21$ & $5 \pm 26$ \\
\hline SF & $83 \pm 24$ & $87 \pm 13$ & $89 \pm 19$ & $6 \pm 17$ \\
\hline VT & $64 \pm 21$ & $75 \pm 22 *$ & $76 \pm 23$ & $12 \pm 24$ \\
\hline $\mathrm{MH}$ & $69 \pm 22$ & $80 \pm 17 *$ & $75 \pm 22$ & $6 \pm 19$ \\
\hline PCS & $41.6 \pm 8.6$ & $43.6 \pm 9.4$ & $44.5 \pm 9.2$ & $2.9 \pm 8.9$ \\
\hline MCS & $52.7 \pm 9.3$ & $54.0 \pm 7.8$ & $53.5 \pm 8.8$ & $0.8 \pm 7.6$ \\
\hline \multicolumn{5}{|c|}{ Lower limbs strength and power } \\
\hline $5 \mathrm{STS}, \mathrm{s}$ & $17.99 \pm 7.98$ & $14.91 \pm 5.88^{* *}$ & $13.02 \pm 6.02 * *$ & $-4.97 \pm 3.54$ \\
\hline $1-\mathrm{RM} \mathrm{FQ}_{\text {weak }}, \mathrm{kg}$ & $18.7 \pm 11.0$ & $21.9 \pm 9.3^{*}$ & $24.5 \pm 10.7 * *$ & $5.8 \pm 5.5$ \\
\hline 1-RM FQ $\mathrm{F}_{\text {strong }}, \mathrm{kg}$ & $22.4 \pm 9.0$ & $24.9 \pm 6.6$ & $30.1 \pm 9.8^{* *}$ & $7.6 \pm 9.0$ \\
\hline $1-\mathrm{RM} \mathrm{FB}_{\text {weak }}, \mathrm{kg}$ & $11.8 \pm 10.6$ & $11.6 \pm 11.1$ & $19.7 \pm 20.0^{* *}$ & $7.8 \pm 10.5$ \\
\hline $1-\mathrm{RM} \mathrm{FB}_{\text {strong }}, \mathrm{kg}$ & $15.4 \pm 12.2$ & $15.8 \pm 10.1$ & $23.5 \pm 11.9^{* *}$ & $8.1 \pm 5.4$ \\
\hline Peak Power FQ $\mathrm{weak}_{\text {we }}, \mathrm{W}$ & $64.2 \pm 57.3$ & $80.0 \pm 53.7 *$ & $111.1 \pm 86.6^{* *}$ & $46.9 \pm 40.5$ \\
\hline Peak Power $\mathrm{FQ}_{\text {strong }}, \mathrm{W}$ & $82.8 \pm 53.2$ & $107.4 \pm 58.9^{* *}$ & $156.2 \pm 99.0^{* *}$ & $73.4 \pm 56.3$ \\
\hline Peak Power FB weak, $\mathrm{W}$ & $31.6 \pm 42.6$ & $30.8 \pm 37.9$ & $52.3 \pm 49.1 * *$ & $20.8 \pm 23.7$ \\
\hline Peak Power $\mathrm{FB}_{\text {strong }}, \mathrm{W}$ & $51.4 \pm 62.9$ & $50.4 \pm 46.0$ & $71.3 \pm 52.0^{*}$ & $19.9 \pm 29.4$ \\
\hline
\end{tabular}

Values are presented as mean $\pm \mathrm{SD}$ for continuous variables.

1-RM: 1-repetition maximum; 10mWS: 10-meter walking speed; 5STS: 5-time sit-to-stand test; BBS: Berg Balance Scale; BP: bodily pain; ER: emotional role; FB: femoral biceps; FQ: femoral quadriceps; GH: general health; MCS: mental component score; MH: mental health; 6MWD: 6-minute walk distance; PCS: physical component score; PF: physical functioning; PR: physical role; QoL: quality of life; Rev: revascularization group; SF: social functioning; SF-36: Short-Form 36 Questionnaire; VT: vitality. \$ Intragroup analysis of variations T8-T0 was performed by unpaired Student's $t$-test or Mann-Whitney U test as appropriate; intergroup analysis was performed by paired Student's $t$-test or Wilcoxon test as appropriate; *P $<0.05 ; * * \mathrm{P}<0.01$. 


\section{COPYRIGHT $^{(\odot)} 2017$ EDIZIONI MINERVA MEDICA}

LOW-INTENSITY TRAINING IN CHRONIC STROKE SURVIVORS

LAMBERTI

found that balance significantly increased after treatment in both groups and at T8 but not at the end of the endurance phase (Table III).

\section{GAIT SPEED}

The $10 \mathrm{mWS}$ data were not significantly different between the groups. However, we noted significant improvements in gait speed for both treatments at $\mathrm{T} 4$ and T8 (Table III).

\section{LOWER-LIMB MUSCLE STRENGTH AND POWER}

At the end of the program, we did not observe any differences in 5STS variations with respect to the baseline data when we compared the two groups. However, both treatments significantly reduced the time to complete the test both at T4 and at T8 (Table III). The strength variations of all of the muscle groups at T8 with respect to the baseline data were not significantly different between the treatments. We found that $\mathrm{FQ}_{\text {weak }}, \mathrm{FB}_{\text {weak }}$ and $\mathrm{FB}_{\text {strong }}$ increased at $\mathrm{T} 8$ for both groups; $\mathrm{FQ}_{\text {strong }}$ exhibited a significant improvement only for the LI-E group (Table III; Figure 3). Higher peak power variations at T8 with respect to T0 were observed for the LI-E group for $\mathrm{FQ}_{\text {weak }}$ and $\mathrm{FQ}_{\text {strong }}(\mathrm{P}=0.008$ and $\mathrm{P} \leq 0.001$, respectively). The peak power of all muscles measured improved after both treatments (Table III; Figure 3). No inter-group differences were noted between T4 and T0. However, we recovered significant variations at $\mathrm{T} 4$ in terms of the strength and peak power of $\mathrm{FQ}_{\text {weak }}(\mathrm{P}=0.027$ and $\mathrm{P}=0.011$, respectively) and for the peak power of $\mathrm{FQ}_{\text {strong }}(\mathrm{P}<0.001)$ for the LI-E group (Figure 3).

\begin{tabular}{|c|c|c|c|c|}
\hline \multicolumn{4}{|c|}{$\begin{array}{l}\text { High-intensity active control group } \\
\qquad(\mathrm{N} .=17)\end{array}$} & \multirow{2}{*}{ P value $\S$} \\
\hline T0 & $\mathrm{T} 4$ & $\mathrm{~T} 8$ & $\Delta \mathrm{T} 8-\mathrm{T} 0$ & \\
\hline $258 \pm 133$ & $274 \pm 132 *$ & $292 \pm 136 * *$ & $35 \pm 32$ & 0.009 \\
\hline $50 \pm 5$ & $52 \pm 4$ & $52 \pm 4$ & $2 \pm 3$ & NS \\
\hline $1.03 \pm 0.46$ & $1.10 \pm 0.46^{*}$ & $1.21 \pm 0.53$ & $0.18 \pm 0.18$ & NS \\
\hline $61 \pm 22$ & $62 \pm 26$ & $65 \pm 26$ & $5 \pm 14$ & 0.012 \\
\hline $78 \pm 26$ & $79 \pm 23$ & $87 \pm 20$ & $9 \pm 25$ & NS \\
\hline $63 \pm 47$ & $63 \pm 43$ & $66 \pm 48$ & $3 \pm 40$ & NS \\
\hline $55 \pm 22$ & $59 \pm 23$ & $58 \pm 27$ & $4 \pm 19$ & NS \\
\hline $61 \pm 32$ & $71 \pm 44$ & $78 \pm 37 *$ & $17 \pm 36$ & NS \\
\hline $73 \pm 25$ & $86 \pm 18 *$ & $81 \pm 25$ & $8 \pm 26$ & NS \\
\hline $61 \pm 23$ & $66 \pm 24$ & $64 \pm 27$ & $3 \pm 12$ & NS \\
\hline $70 \pm 19$ & $72 \pm 20$ & $73 \pm 22$ & $3 \pm 15$ & NS \\
\hline $44.5 \pm 9.0$ & $43.0 \pm 8.6$ & $45.5 \pm 9.6$ & $1.0 \pm 4.8$ & NS \\
\hline $47.9 \pm 11.3$ & $51.9 \pm 10.4$ & $51.3 \pm 11.1$ & $4.1 \pm 8.3$ & NS \\
\hline $20.41 \pm 19.25$ & $14.39 \pm 6.15^{* *}$ & $13.00 \pm 4.96^{* *}$ & $-7.41 \pm 16.63$ & NS \\
\hline $18.5 \pm 10.2$ & $20.7 \pm 9.0$ & $23.9 \pm 13.2^{*}$ & $5.4 \pm 8.4$ & NS \\
\hline $28.1 \pm 17.1$ & $30.5 \pm 19.4$ & $30.1 \pm 18.2$ & $1.9 \pm 8.5$ & NS \\
\hline $9.6 \pm 7.9$ & $10.2 \pm 6.9$ & $14.0 \pm 9.9 *$ & $4.4 \pm 5.4$ & NS \\
\hline $11.7 \pm 4.9$ & $13.4 \pm 4.3$ & $17.9 \pm 7.5 * *$ & $6.2 \pm 5.6$ & NS \\
\hline $62.6 \pm 40.6$ & $66.1 \pm 36.8$ & $78.3 \pm 44.2 *$ & $15.7 \pm 21.2$ & 0.007 \\
\hline $96.4 \pm 55.0$ & $93.0 \pm 54.8$ & $112.4 \pm 57.0 *$ & $16.0 \pm 31.0$ & $<0.001$ \\
\hline $22.2 \pm 18.9$ & $20.4 \pm 16.6$ & $30.7 \pm 27.0 *$ & $8.5 \pm 13.5$ & NS \\
\hline $33.8 \pm 15.5$ & $39.0 \pm 18.0$ & $44.7 \pm 21.2^{*}$ & $10.9 \pm 17.6$ & NS \\
\hline
\end{tabular}




\section{COPYRIGHT ${ }^{\odot} 2017$ EDIZIONI MINERVA MEDICA}

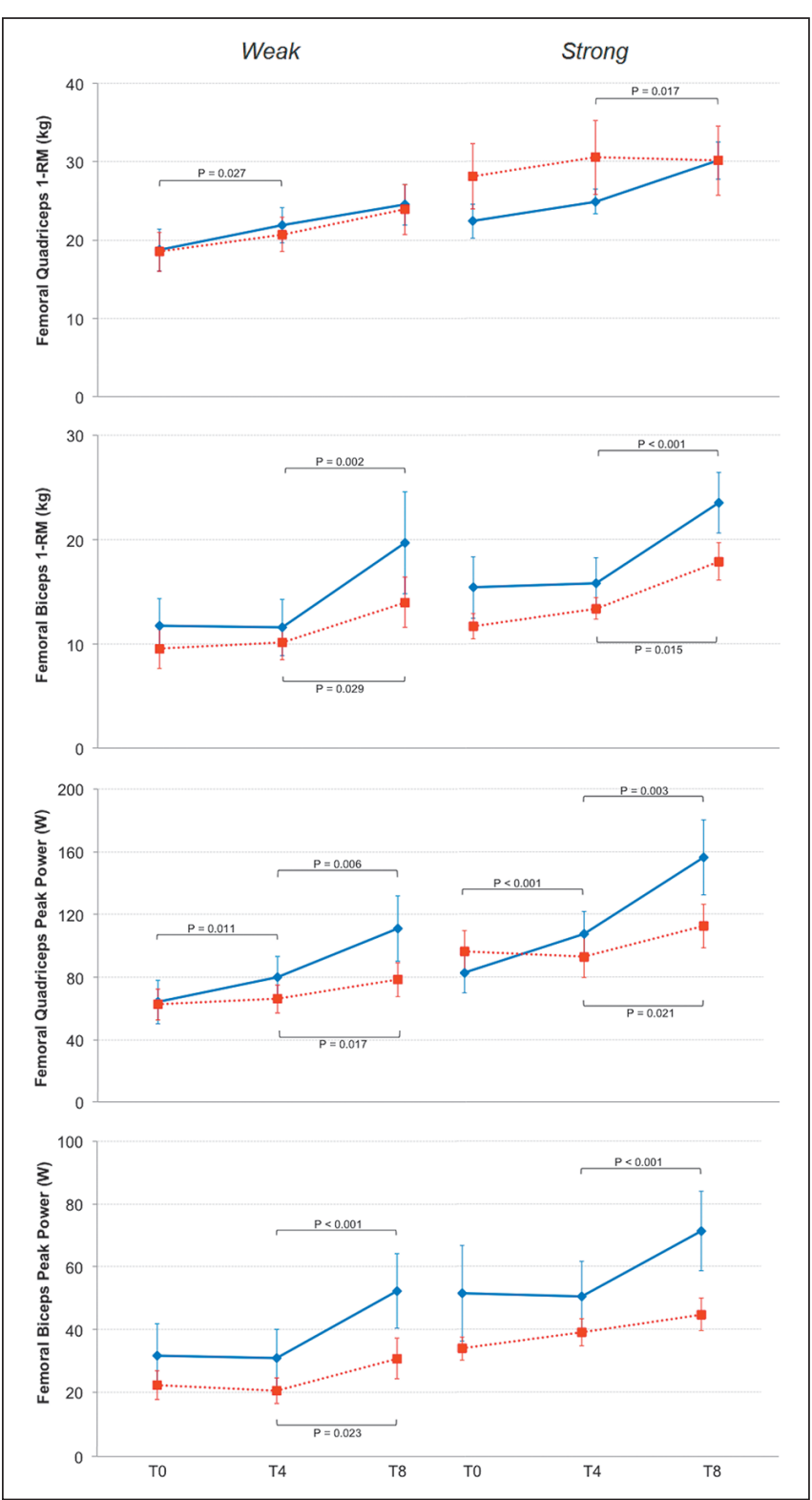

Figure 3.-Tendencies of strength and peak power of femoral quadriceps and biceps classified as weak and strong limb at the three assessment times.

Diamonds represent the LI-E group, squares the HI-C group. Data are presented as mean \pm standard error of the mean. Within groups analysis was performed by Student's $t$-test or Wilcoxon test, as appropriate.

T0: baseline; T4: end of the endurance phase; T8: end of treatment.

\section{MUSCLE PERFORMANCE AND MOBILITY}

At baseline, 6MWD was strongly correlated with strength and power of $\mathrm{FQ}_{\text {weak }}, \mathrm{FQ}_{\text {strong }}$, and $\mathrm{FB}_{\text {weak }}$; we noted higher degrees of correlation for the strength and peak power of $\mathrm{FB}_{\text {weak }}(r=0.62, \mathrm{P}<0.001$, and $r=0.61$, $\mathrm{P}<0.001$, respectively). At T8, 6MWD remained significantly correlated only with the peak power of $\mathrm{FQ}_{\text {weak }}$ $(r=0.37, \mathrm{P}=0.029)$ and $\mathrm{FB}_{\text {weak }}(r=0.53, \mathrm{P}=0.001)$.

\section{Discussion}

The main finding derived from this pilot study when we compared the two 8-week progressive endurance and resistance supervised training programs in untrained chronic stroke survivors - was that patients in the LI-E group exhibited significantly more improvement in mobility than patients in the HI-C group. Considering the 6MWD to be representative of the self-selected gait speed, $67 \%$ of patients in the LI-E group versus $18 \%$ of patients in the HI-C group attained the estimated clinically important change value of $10.5 \mathrm{~m} / \mathrm{min} .{ }^{34}$ A significant improvement in the PF domain of the SF-36 questionnaire and in the peak power of the FQ was also observed in the LI-E group but not the HI-C group. However, patients in both groups exhibited significant intragroup improvements in functional parameters over the 24-session period. Interestingly, the LI-E group performed endurance training (interval over-ground walking) at a lower percentage of HRR and resistance training (muscle power training) at a lower percentage of the maximal load than patients in the HI-C group who performed continuous treadmill walking and muscle-strength training. A number of studies have reported the effects of mixed endurance and resistance training programs 16,22 with some evidence of improvement in walking performance. ${ }^{16}$ However, to the best of our knowledge, no trial has included power training as a component of a rehabilitation program (as we did). Notably, from our preliminary analysis, muscle power emerged as the only determinant of mobility after 8 weeks in our entire population.

The mode and intensity of exercise may offer a key to interpreting the more favorable mobility outcomes observed in the LI-E group. After the 4 weeks of the endurance phase, a higher 6MWD change in LI-E patients versus $\mathrm{HI}-\mathrm{C}$ patients was already observable. Treadmill training is considered to be effective for the rehabilitation of chronic stroke patients compared with usual physiotherapy care ${ }^{35}$ also enabling to decrease 


\section{COPYRIGHT $^{(} 2017$ EDIZIONI MINERVA MEDICA}

patient's body weight, as well to increase the grade instead of speed. ${ }^{6}$ However, ground walking might offer higher specificity, one of the FITT principles, paralleling real-life conditions. Improved balance and fewer falls over a 6-month period following over-ground gait training compared with treadmill training, ${ }^{36}$ as well as increased walking efficiency, ${ }^{37}$ have been reported. The experimental program required $30-40 \%$ lower HHR than treadmill training; training intensity accordingly emerges as a key factor to be considered. The program is based on short bouts of interval exercise at a prescribed and controlled speed, which is lower than habitual walking speed, with a progressive increase in speed. Despite the superior external load (faster median walking speed) of the LI-E group, the interval structure of the exercise resulted in lower relative physiological stress, the so-called internal load, as demonstrated by the lower HRR. 38 The model, which we carried out here under supervision, has been successfully employed in chronic diseases. ${ }^{23-25}$ A "similar" exercise program carried out at gradually increasing intensity from low to high speed in rats who suffered from focal ischemic stroke yielded significantly better motor function rehabilitation when compared with a stable, high-intensity program. ${ }^{39}$ In peripheral arterial disease patients, this training at a controlled speed lower than the self-selected gait speed resulted in positive aerobic muscular adaptations in more ischemic limbs. ${ }^{40}$ Such aerobic stimuli may therefore improve muscle deconditioning as well as muscle wasting and inflammation of skeletal muscles on the stroke-affected side; it is on this side that fiber conversion from slow-twitch to fast-twitch and a reduction in capillarization occur. ${ }^{41}$ The Endurance phase also enhanced both the strength and peak power of $\mathrm{FQ}_{\text {weak }}$ only in the LI-E group; the stand-up movement after every 1-minute rest period might have represented an additional stimulus for the FQ. As a final observation, it should be noted that neither walking program improved muscle performance of the FB, thereby suggesting that sessions of training for the flexor muscles should be added into walking training programs for stroke survivors. The Mixed phase led to a significant additional improvement in 6MWD in both groups. This finding confirmed-despite previous conflicting results $18,20,21$ — that mixed training is an effective rehabilitative modality. Moreover, we observed a significant change in peak power at $\mathrm{FQ}_{\text {weak }}$ and $\mathrm{FQ}_{\text {strong }}$ in the LI-E group compared with the HI-C group. Gains in muscle strength and power following both training protocols were observed, and these gains, which were particularly pronounced for power, were larger (1.5- to 4-fold) in the LI-E group. Peak muscle power is typically set at approximately $70 \%$ of the 1-RM; however, maximal contraction velocity typically occurs at a lower external resistance $(40 \%$ of $1-\mathrm{RM}),{ }^{42}$ which corresponds to the training load prescribed to the LI-E group, maintained at optimal speed by the feedback provided by the linear encoder previously described. Observational studies have reported strong associations between muscle performance (paretic knee-extension torque or hip flexor and ankle plantar flexor strength) and locomotion ability after stroke, ${ }^{43}$ even if interventions with a statistically significant effect on strength failed to demonstrate significant improvements in walking. ${ }^{15}$ Post-stroke motor control was found to be affected by a significant reduction in muscle power generation, 44 and improvements in walking speed were observed following lower-limb muscle strength and power training. ${ }^{44}$ These findings suggest that muscle power training should be a part of rehabilitation. ${ }^{45}$ At the end of our study's program, only the peak power parameters of the weaker limbs were correlated with mobility. This preliminary finding highlights that muscle power is a critical contributor of performance and PF in both older adults 42 and stroke survivors. ${ }^{45}$ The sustainability of the model of exercise that we propose is another issue worthy of discussion. Exercise prescription in special populations, including stroke survivors, is comparable to drug prescription; a personalized dosage (in terms of, for example, frequency, intensity, time and type) to avoid under- or overdosing has to be identified. ${ }^{6}$ High-intensity protocols (e.g., $60-80 \%$ of the HRR, ${ }^{46}$ or $85-95 \%$ of $\left.1-\mathrm{RM}\right){ }^{47}$ have been effective at yielding improvements in functional capacity compared with conventional physical therapy. In this pilot study, we showed that a low dose of exercise was able to produce significant benefits compared with a comparable, more-intense protocol. The definition of the minimal load sufficient to yield significant benefits may increase the number of patients eligible for training, may yield better safety in terms of the comorbidities of stroke patients (e.g., heart disease) and may reduce the risk of cardiac complications during rehabilitation. ${ }^{48}$ A minimal load may 


\section{COPYRIGHT $^{(} 2017$ EDIZIONI MINERVA MEDICA}

also reduce the risk of injury and the likelihood that patients will withdraw from rehabilitation programs due to musculoskeletal pain, low-functional reserve, low fatigue thresholds, fatigue and perceived self-efficacy barriers to participating in exercise training. ${ }^{49}$ In addition, social barriers must be taken into account when designing exercise programs; costs, lack of availability to fitness resources, lack of transportation, accessibility and family support are relevant in limiting participation. ${ }^{49}$ The experimental training model described here seems to be feasible and sustainable. The power training was performed by a linear encoder instead of an isokinetic machine. The necessary equipment (encoder, ankle weights, metronomes) for experimental training costs approximately $€ 3500$, significantly less than the cost of the gym machines used to train the patients in the HI-C group. The devices are easily transportable in a small piece of luggage, which means that physiotherapists or exercise specialists can work with stroke survivors to ensure functional recovery even in poorly equipped, community-based settings. Finally, the present program may be transferable in its maintenance phase to home-based training, as has already been done for similar chronic diseases. ${ }^{23-25}$

\section{Limitations of the study}

The study has a number of limitations. First of all, it lacks a control inactive group. We additionally did not carry out two separate baseline measures for the patients enrolled. The statistical analysis for each outcome measurement, performed considering changes between T0 and T8, could have been influenced by possible baseline differences, even not significant. A follow-up measure was not included in the study. However, none of the patients would have wanted to stop the physical activity program begun at the adapted physical activity center. In addition, the assessors were not blinded to the treatment. Finally, despite being a pilot study, the small size of both groups might have partly influenced the results obtained.

\section{Conclusions}

In conclusion, this study of chronic stroke survivors highlights the effects of exercise training on mobility after only 8 weeks of progressive and personalized treatment. We preliminary observed better results for aerobic and muscular stimuli with a lower but precisely set intensity both for the endurance phase and for the mixed phase. A larger trial that includes follow-up observations will be necessary to confirm the present data and to examine whether the training effects are retained at follow-up.

\section{References}

1. Koivusalo M, Mackintosh M. The World Health Report 2007. A Safer Future: Global Public Health Security in the 21st Century, Development and Change 2008, Volume 39. Geneva: World Health Organization 2007. p. 1163-9.

2. Go AS, Mozaffarian D, Roger VL, Benjamin EJ, Berry JD, Borden WB, et al. Heart disease and stroke statistics - 2013 update: a report from the American Heart Association. Circulation 2013;127:e6e245.

3. Truelsen T, Piechowski-Jozwiak B, Bonita R, Mathers C, Bogousslavsky J, Boysen G. Stroke incidence and prevalence in Europe: a review of available data. Eur J Neurol 2006;13:581-98.

4. American Heart Association Statistics Committee and Stroke Statistics Subcommittee. Heart disease and stroke statistics--2007 update: a report from the American Heart Association Statistics Committee and Stroke Statistics Subcommittee. Circulation 2007;115:e69-171.

5. Bohannon RW, Horton MG, Wikholm JB. Importance of four variables of walking to patients with stroke. Int J Rehabil Res 1991;14:24650 .

6. Billinger SA, Arena R, Bernhardt J, Eng JJ, Franklin BA, Johnson $\mathrm{CM}$, et al.; American Heart Association Stroke Council; Council on Cardiovascular and Stroke Nursing; Council on Lifestyle and Cardiometabolic Health; Council on Epidemiology and Prevention; Council on Clinical Cardiology. Physical activity and exercise recommendations for stroke survivors: a statement for healthcare professionals from the American Heart Association/American Stroke Association. Stroke 2014;45:2532-53.

7. Lamb SE, Ferrucci L, Volapto S, Fried LP, Guralnik JM, Women's Health and Aging Study. Risk factors for falling in home-dwelling older women with stroke: the Women's Health and Aging Study. Stroke 2003;34:494-501.

8. Cornelissen VA, Arnout J, Holvoet P, Fagard RH. Influence of exercise at lower and higher intensity on blood pressure and cardiovascular risk factors at older age. J Hypertens 2009;27:753-62.

9. Naci H, Ioannidis JP. Comparative effectiveness of exercise and drug interventions on mortality outcomes: metaepidemiological study. $\mathrm{Br}$ J Sports Med 2015;49:1414-22.

10. Ryan AS, Ivey FM, Prior S, Li G, Hafer-Macko C. Skeletal Muscle Hypertrophy and Muscle Myostatin Reduction after Resistive Training in Stroke Survivors. Stroke 2011;42:416-20.

11. Stoller O, de Bruin ED, Knols RH, Hunt KJ. Effects of cardiovascular exercise early after stroke: systematic review and meta-analysis. BMC Neurol 2012;12:45.

12. Pang MY, Eng JJ, Dawson AS, Gylfadottir S. The use of aerobic exercise training in improving aerobic capacity in individuals with stroke: a meta-analysis. Clin Rehabil 2006;20:97-111.

13. Veerbeek JM, Koolstra M, Ket JC, van Wegen EE, Kwakkel G. Effects of augmented exercise therapy on outcome of gait and gait-related activities in the first 6 months after stroke: a meta-analysis. Stroke 2011;42:3311-15.

14. van de Port IG, Wood-Dauphinee S, Lindeman E, Kwakkel G. Effects of exercise training programs on walking competency after stroke: a systematic review. Am J Phys Med Rehabil 2007;86:935-51.

15. Wist S, Clivaz J, Sattelmayer M. Muscle strengthening for hemipare- 


\section{COPYRIGHT ${ }^{\odot} 2017$ EDIZIONI MINERVA MEDICA}

LOW-INTENSITY TRAINING IN CHRONIC STROKE SURVIVORS

LAMBERTI

sis after stroke: A meta-analysis. Ann Phys Rehabil Med 2016;59:11424.

16. Saunders DH, Sanderson M, Hayes S, Kilrane M, Greig CA, Brazzelli M, et al. Physical fitness training for stroke patients. Cochrane Database Syst Rev 2016;3:CD003316.

17. Smith AC, Saunders DH, Mead G. Cardiorespiratory fitness after stroke: a systematic review. Int J Stroke 2012;7:499-510.

18. Bell GJ, Syrotuik D, Martin TP, Burnham R, Quinney HA. Effect of concurrent strength and endurance training on skeletal muscle properties and hormone concentrations in humans. Eur J Appl Physiol 2000;81:418-27.

19. Nelson AG, Arnall DA, Loy SF, Silvester LJ, Conlee RK. Consequences of combining strength and endurance training regimens. Phys Ther 1990;70:287-94.

20. Karavirta L, Häkkinen A, Sillanpää E, García-López D, Kauhanen A, Haapasaari A, et al. Effects of combined endurance and strength training on muscle strength, power and hypertrophy in 40-67-yearold men. Scand J Med Sci Sports 2011;21:402-11.

21. MacNeil LG, Glover E, Bergstra TG, Safdar A, Tarnopolsky MA. The order of exercise during concurrent training for rehabilitation does not alter acute genetic expression, mitochondrial enzyme activity or improvements in muscle function. PLoS One 2014;9:e109189.

22. Ammann BC, Knols RH, Baschung P, de Bie RA, de Bruin ED. Application of principles of exercise training in sub-acute and chronic stroke survivors: a systematic review. BMC Neurol 2014;14:167.

23. Malagoni AM, Catizone L, Mandini S, Soffritti S, Manfredini R, Boari B, et al. Acute and long-term effects of an exercise program for dialysis patients prescribed in hospital and performed at home. J Nephrol 2008;21:871-8.

24. Malagoni AM, Cavazza S, Ferraresi G, Grassi G, Felisatti M, Lamberti $\mathrm{N}$, et al. Effects of a "test in-train out" walking program versus supervised standard rehabilitation in chronic stroke patients: a feasibility and pilot randomized study. Eur J Phys Rehabil Med 2016;52:279-87.

25. Malagoni AM, Vagnoni E, Felisatti M, Mandini S, Heidari M, Mascoli $\mathrm{F}$, et al. Evaluation of patient compliance, quality of life impact and cost-effectiveness of a "test in-train out" exercise-based rehabilitation program for patients with intermittent claudication. Circ J 2011;75:2128-34.

26. Pigozzi F, Giombini A, Macaluso A. Do current methods of strength testing for the return to sport after injuries really address functional performance? Am J Phys Med Rehabil 2012;91:458-60.

27. Ivey FM, Hafer-Macko CE, Macko RF. Task-oriented treadmill exercise training in chronic hemiparetic stroke. J Rehabil Res Dev 2008;45:249-59.

28. Ouellette MM, LeBrasseur NK, Bean JF, Phillips E, Stein J, Frontera WR, et al. High-Intensity Resistance Training Improves Muscle Strength, Self-Reported Function, and Disability in Long-Term Stroke Survivors. Stroke 2004;35:1404-9.

29. Flansbjer UB, Holmbäck AM, Downham D, Patten C, Lexell J. Reliability of gait performance tests in men and women with hemiparesis after stroke. J Rehabil Med 2005;37:75-82.

30. Apolone G, Mosconi P. The Italian SF-36 Health Survey: translation, validation and norming. J Clin Epidemiol 1998;51:1025-36.

31. Berg K, Wood-Dauphinee S, Williams JI. The Balance Scale: reliability assessment with elderly residents and patients with an acute stroke. Scand J Rehabil Med 1995;27:27-36.

32. Mong Y, Teo TW, Ng SS. 5-repetition sit-to-stand test in subjects with chronic stroke: reliability and validity. Arch Phys Med Rehabil 2010;91:407-13

33. Kostka T, Rahmani A, Berthouze SE, JR Lacour, Bonnefoy M. Quadriceps Muscle Function in Relation to Habitual Physical Activity and $\mathrm{O}_{2}$ max in Men and Women Aged More Than 65 Years. J Gerontol A Biol Sci Med Sci 2000;55A:481-8.

34. Fulk GD, Ludwig M, Dunning K, Golden S, Boyne P, West T. Estimating clinically important change in gait speed in people with stroke undergoing outpatient rehabilitation. J Neurol Phys Ther 2011;35:829.

35. Macko RF, Ivey FM, Forrester LW, Hanley D, Sorkin JD, Katzel LI, et al. Treadmill exercise rehabilitation improves ambulatory function and cardiovascular fitness in patients with chronic stroke: a randomized, controlled trial. Stroke 2005;36:2206-11.

36. Dean CM, Ada L, Bampton J, Morris ME, Katrak PH, Potts S. Treadmill walking with body weight support in subacute non-ambulatory stroke improves walking capacity more than overground walking: a randomised trial. J Physiother 2010;56:97-103.

37. Brouwer B, Parvataneni K, Olney SJ. A comparison of gait biomechanics and metabolic requirements of overground and treadmill walking in people with stroke. Clin Biomech 2009;24:729-34.

38. Halson SL. Monitoring training load to understand fatigue in athletes. Sports Med 2014;44(Suppl 2):S139-47.

39. Sun J, Ke Z, Yip SP, Hu XL, Zheng XX, Tong KY. Gradually increased training intensity benefits rehabilitation outcome after stroke by BDNF upregulation and stress suppression. Biomed Res Int 2014;2014:925762.

40. Manfredini F, Malagoni AM, Felisatti M, Mandini S, Mascoli F, Manfredini R, et al. A dynamic objective evaluation of peripheral arterial disease by near-infrared spectroscopy. Eur J Vasc Endovasc Surg 2009;38:441-8.

41. Billinger SA, Coughenour E, Mackay-Lyons MJ, Ivey FM. Reduced cardiorespiratory fitness after stroke: biological consequences and exercise-induced adaptations. Stroke Res Treat 2012;2012:959120.

42. Reid KF, Fielding RA. Skeletal muscle power: a critical determinant of physical functioning in older adults. Exerc Sport Sci Rev 2012;40:4-12.

43. Olney SJ, Griffin MP, Monga TN, McBride ID. Work and power in gait of stroke patients. Arch Phys Med Rehabil 1991;72:309-14.

44. Morgan P, Embry A, Perry L, Holthaus K, Gregory CM. Feasibility of lower-limb muscle power training to enhance locomotor function poststroke. J Rehabil Res Dev 2015;52:77-84.

45. Stavric VA, McNair PJ. Optimizing muscle power after stroke: a cross-sectional study. J Neuroeng Rehabil 2012;9:67.

46. Globas C, Becker C, Cerny J, Lam JM, Lindemann U, Forrester LW, et al. Chronic stroke survivors benefit from high-intensity aerobic treadmill exercise: a randomized control trial. Neurorehabil Neural Repair 2012;26:85-95.

47. Hill TR, Gjellesvik TI, Moen PM, Tørhaug T, Fimland MS, Helgerud $\mathrm{J}$, et al. Maximal strength training enhances strength and functional performance in chronic stroke survivors. Am J Phys Med Rehabil 2012;91:393-400

48. Roth EJ, Mueller K, Green D. Stroke rehabilitation outcome: impact of coronary artery disease. Stroke 1988;19:42-7.

49. Rimmer JH, Wang E, Smith D. Barriers associated with exercise and community access for individuals with stroke. J Rehabil Res Dev $2008 ; 45: 315-22$

Funding.-The study was partly supported by a grant from the Camera di Commercio, Industria, Artigianato e Agricoltura di Ferrara, and by a grant from the Fondo di Ateneo per la Ricerca of the University of Ferrara.

Conflicts of interest.-The authors certify that there is no conflict of interest with any financial organization regarding the material discussed in the manuscript. Congresses.-Preliminary data from this study were presented at the $54^{\text {th }}$ International Neuropsychiatric Pula Congress, which was held on June $18^{\text {th }}-21^{\text {st }}$, 2014 in Pula, Croatia, and at the 43rd National Congress of the Italian Society of Physical and Rehabilitation Medicine (SIMFER), which took place on October $4^{\text {th }}$-7th, 2015 in Ferrara, Italy (poster \#52).

Article first published online: September 14, 2016. - Manuscript accepted: September 12, 2016. - Manuscript revised: September 2, 2016. - Manuscript received: April 22, 2016. 